\title{
AS PERCEPÇÕES DE PROFESSORES DE LÍNGUA INGLESA EM FORMAÇÃO SOBRE ESTRATÉGIAS APLICADAS AO ENSINO E APRENDIZAGEM
}

\author{
LAS PERCEPCIONES DE PROFESORES DE LENGUA INGLESA EN FORMACIÓN \\ SOBRE ESTRATEGIAS APLICADAS A LA ENSEÑANZA Y APRENDIZAJE
}

\author{
PRE-SERVICE ENGLISH TEACHERS' PERCEPTIONS ABOUT STRATEGIES USED \\ IN THE TEACHING-LEARNING PROCESS
}

\author{
Fabiana Vanessa Achy de ALMEIDA ${ }^{1}$ \\ Andressa BRAWERMAN-ALBINI ${ }^{2}$
}

RESUMO: O conhecimento sobre o uso de estratégias de aprendizagem é essencial para capacitar estudantes e futuros professores de línguas como mais reflexivos, autônomos e corresponsáveis pelo seu aprendizado. Assim, o objetivo deste trabalho é descrever a percepção de professores de língua inglesa em formação sobre estratégias aplicadas ao ensino e aprendizagem de línguas. Participaram desta pesquisa 30 alunos da disciplina de Prática de Ensino em Língua Inglesa do curso de Licenciatura em Letras Português-Inglês. A coleta de dados consistiu na aplicação de um Questionário Metacognitivo acerca do uso de estratégias para ensino e aprendizagem de língua inglesa. Os resultados foram analisados qualitativamente e mostram que os participantes detêm uma ampla consciência sobre seu aprendizado e sobre o uso de estratégias. Mais ainda, os resultados apontam uma concepção positiva quanto ao uso das estratégias e uma base teórica para repassar esse conhecimento aos seus futuros alunos na carreira docente.

PALAVRAS-CHAVE: Ensino-aprendizagem. Língua inglesa. Estratégias. Metacognição. Professores em formação.

RESUMEN: El conocimiento sobre el uso de estrategias de aprendizaje es esencial para la capacitación de estudiantes y futuros profesores de lenguas más reflexivas, autónomas y corresponsables por su aprendizaje. El objetivo de este trabajo es describir la percepción de profesores de la lengua inglesa en formación sobre estrategias aplicadas a la enseñanza y aprendizaje de lenguas. Participarón 30 alumnos de disciplina de Práctica de la Enseñanza de Lengua Inglesa del curso de Licenciatura en Letras Portugués-Inglés. La colecta de datos consistió en la aplicación de un Cuestionario Metacognitivo acerca del uso de estrategias para la enseñanza y aprendizaje de la lengua inglesa. Los resultados fueron analizados cualitativamente y demuestraron que los participantes detienen una amplia conciencia sobre su aprendizaje y sobre el uso de estrategias, y una concepción positiva al uso de las estrategias

\footnotetext{
${ }^{1}$ Universidade Tecnológica Federal do Paraná (UTFPR), Curitiba - PR - Brasil. Professora do Departamento Acadêmico de Línguas Estrangeiras Modernas. ORCID <http://orcid.org/0000-0002-5103-1283>. E-mail: fabianaalmeida@utfpr.edu.br

${ }^{2}$ Universidade Tecnológica Federal do Paraná (UTFPR), Curitiba - PR - Brasil. Professora do Departamento Acadêmico de Línguas Estrangeiras Modernas. ORCID <https://orcid.org/0000-0003-1402-4145>. E-mail: andbraw@utfpr.edu.br
} 
y una base teórica para transmitir ese conocimiento a sus futuros alumnos en la carrera docente.

PALABRAS CLAVE: Enseñanza y aprendizaje. Lengua inglesa. Estratégias. Metacognición. Profesores en formación.

ABSTRACT: Learning what strategies are and their use is essential to form more critical and autonomous foreign language learners and pre-service teachers. Thus, the objective of this study is to describe the perception of pre-service English teachers on strategies applied to teaching and learning languages. In this research, the participants were 30 students of the Teaching Practice in English Language course from the Arts English Language and Literature Department that took part in this study. The data collection consisted of the application of a Metacognitive Questionnaire about the use of strategies for teaching and learning English. The results were analyzed qualitatively and showed that participants have a broad awareness of their learning and the use of strategies. Moreover, results point to a positive conception about their use of strategies and a theoretical basis to teach this content to future students in the teaching career.

KEYWORDS: Teaching-learning. English language. Strategies. Metacognition. Pre-service teachers.

\section{Introdução}

A literatura e o campo investigativo sobre formação de professores de línguas têm informado quantitativa e qualitativamente as concepções teórico-metodológicas em ensino e aprendizagem de língua estrangeira e/ou adicional ${ }^{3}$. Johnson e Dellagnello (2015) observam que aproximadamente quatro décadas de pesquisa com foco na cognição do professor e, em menor extensão, na formação de professores de segunda língua, tendem a caracterizar a aprendizagem do ensino como um processo de apropriação de padrões culturalmente valorizados, de acordo com o contexto social no qual os professores estão inseridos. As autoras explicam que essa premissa define as formas de agir e interagir dos professores, refletindo seus valores, pressupostos e atitudes. Em contrapartida, esse comportamento retrata os padrões de sala de aula onde os professores foram alunos, como alunos em programas de formação de professores, ou em escolas onde os professores trabalham ou irão trabalhar.

Portanto, a perspectiva mais contemporânea e sociointeracionista sobre formação de docentes indica que o contexto no qual o trabalho do professor é exercido tem papel preponderante em determinar suas concepções sobre sua profissão. Mais ainda, uma das

${ }^{3}$ Não é objetivo deste trabalho discutir a distinção que há na literatura entre os conceitos de língua estrangeira (FL), língua adicional (LA) e segunda língua (L2), apesar de reconhecermos a sua relevância para o campo investigativo. Para fins deste estudo, usamos os termos como sinônimos. 
premissas no campo de formação de professores considera que ensinar é um processo, o qual se inicia muito antes da situação de sala de aula. Desse modo, ponderam Johnson e Dellagnello (2015):

In both teaching and the learning of teaching it is essential that L2/FL teachers are able to make theoretically and pedagogically sound judgments about the instructional issues to be worked on and, to identify the resources that are necessary to support quality L2/FL student learning (JOHNSON; DELLAGNELLO, 2015, p. 15)

Nesse processo de formação é fundamental que o professor tenha entendimento sobre como ocorre a construção da sua cognição. O fato de o indivíduo ter compreensão sobre o seu processo de conhecimento, incluindo o processo de aprendizagem, é chamado de metacognição, sendo definida na literatura como thinking about thinking (CARRELL, 1998; SCHMIDT, 1995). A metacognição refere-se à compreensão e ao reconhecimento de uma situação de aprendizagem, a qual torna o aluno capaz de decidir criticamente como lidar com seu processo de formação de conhecimento, escolhendo as estratégias a serem empregadas, intencionalmente ou não, conforme a situação de aprendizagem. A literatura parece concordar que há dois fatores determinantes para que o aluno realize com sucesso uma tarefa de aprendizado (e aqui esclarecemos que consideramos o professor em formação como aluno). $\mathrm{O}$ primeiro fator descreve que o aluno deve ter um objetivo específico para a tarefa, isto é, deve abordar o exercício tendo em mente o que deseja extrair da empreitada. O segundo fator pressupõe que a tarefa deve ser relevante de algum modo para o aluno, isto é, a tarefa deve conectar-se de alguma forma com a sua realidade (ALMEIDA, 2010; ANDERSON, 2015).

Uma vez que a maior parte da informação que recebemos e que forma nosso conhecimento vem por meio da leitura, a habilidade leitora é igualmente significativa para as concepções teóricas e metodológicas de ensino e aprendizagem e formação de professor de línguas. $\mathrm{O}$ acesso à informação por meio da leitura possibilita a interação do leitor com o texto, e com outros leitores, na construção de sentido e na aquisição de novos conhecimentos. Nesse sentido, apesar de a leitura ser um processo privado ao leitor, é a interação entre o leitor e o texto, tanto quanto a interação entre o leitor e outros leitores, que caracteriza a leitura como um processo ativo (AEBERSOLD; FIELD, 2006; ALMEIDA, 2016; DAVIES, 1995). Ademais, a interação na construção do sentido e na aquisição de conhecimentos é influenciada por outros

${ }^{4}$ Tanto no ensino como na aprendizagem do ensino, é essencial que os professores de L2 / FL sejam capazes de fazer escolhas teoricamente e pedagogicamente sólidas sobre as questões instrucionais a serem trabalhadas e identificar os recursos necessários para apoiar a aprendizagem de qualidade do aluno de L2 / FL (JOHNSON; DELLAGNELLO, 2015, p. 15) (nossa tradução livre). 
fatores intrínsecos e extrínsecos ao leitor, como por exemplo, a motivação e o objetivo da leitura, o grau de conhecimento prévio do leitor, estilos de aprendizagem e o uso de estratégias, para citar alguns.

Mais especificadamente, o conhecimento sobre o que são as estratégias e como usá-las adequada e efetivamente parece também ser crucial na formação crítica do professor de línguas. Podemos considerar o tópico estratégias como tendo objetivo duplo, pois as estratégias podem ser empregadas para aperfeiçoar tanto a aprendizagem do ensino, como para aprimorar o processo per se. Os teóricos parecem não ter chegado a um consenso quanto ao conceito de estratégia, sendo frequentemente definido por seus sinônimos, como por exemplo, ferramenta, instrumento, abordagem, ação, técnica. Contudo, parece haver um consenso de que o grau de metacognição que o aluno possui o auxilia na escolha de qual estratégia será a mais eficaz para a situação de aprendizagem atual. Isso significa que há uma variação no continuum entre habilidade e estratégia, isto é, o grau de discernimento do aluno oscila, respectivamente, entre um conhecimento procedural, mais implícito e automático, e um conhecimento declarativo, mais explícito e mais controlado (ALMEIDA, 2010; ANDERSON, 2015; CARRELL; 1998).

O grau de discernimento sobre conhecimento necessário para a formação tanto do aluno de línguas, quanto para o professor, engloba outros aspectos como a aquisição de vocabulário, o ensino da gramática, as técnicas de escrita e o uso da tradução. Tais elementos também podem ser entendidos como estratégias de ensino e aprendizagem, uma vez que podem ser manipulados como conhecimento mais declarativo ou mais procedural. Infelizmente, excede o objetivo deste estudo examinar essas questões. No entanto, os domínios de vocabulário, gramática, escrita e tradução foram incluídos no instrumento de coleta de dados desta pesquisa como exemplos de estratégias disponíveis para os alunos e futuros professores de língua inglesa. O importante é observar que o grau de discernimento, ou metacognição, que o professor em formação possui é determinante para a consolidação de seu conhecimento. Além disso, o futuro professor mais consciente de seu processo de aprendizado terá maiores chances, e mais motivos relevantes, de ensinar com sucesso as mesmas técnicas para seus alunos.

Tendo em vista as breves considerações expostas, o objetivo do presente trabalho é descrever as percepções sobre estratégias aplicadas ao ensino e aprendizagem de língua inglesa de 30 professores em formação, alunos regularmente matriculados no curso de Licenciatura em Letras Português-Inglês, oferecido em uma universidade tecnológica urbana no sul do país. Os alunos frequentaram aulas de língua inglesa durante quatro semestres, o equivalente a 540 horas/aula formais, bem como assistiram a outras disciplinas de conteúdo crítico, ministradas em português e em inglês. Todos os participantes responderam a um Questionário 
Metacognitivo com perguntas sobre suas percepções sobre estratégias empregadas no processo de aprendizagem em língua inglesa.

Este artigo está organizado em cinco partes. A primeira consiste nesta breve introdução do tema e do objetivo que norteia este estudo. Em seguida, uma concisa revisão bibliográfica é feita a fim de dar o suporte teórico para a pesquisa. A metodologia com os procedimentos utilizados na coleta de dados é descrita posteriormente. A quarta parte do artigo relata e discute os resultados da pesquisa. Por fim, as considerações finais são expostas.

\section{Formação de professores de línguas estrangeiras}

Freeman e Johnson (1998) entendem que a formação de professores constitui um processo de aprendizado, uma tentativa de responder ao questionamento Who teaches what to whom? (p. 405). Sugerem, ainda, três aspectos a serem considerados quando da condução da pesquisa científica na área: o primeiro consiste na atividade de ensinar propriamente dita; o segundo observa o professor; e o terceiro examina a pedagogia aplicada ao ensinar. Todos os três aspectos são estudados tendo em vista uma formação profissional que abarca não somente uma perspectiva epistemológica, examinando-se a natureza do conhecimento e a base teórica, como também uma perspectiva prática por meio da mediação.

Johnson (2009) expande essa compreensão e elenca três outros fatores a serem ponderados no que tange à formação de professores de línguas estrangeiras. $\mathrm{O}$ primeiro fator questiona como os professores adquiriam o conhecimento que possuem. O segundo trata de como alguns conceitos desenvolvem-se durante o tempo para o professor. Finalmente, o terceiro aspecto analisa como o processo de formação transforma o professor e suas atividades de ensino em língua estrangeira. No entanto, a autora chama a atenção para a questão que persiste no centro da discussão da perspectiva sociocultural na formação do docente, isto é, de que o conhecimento do professor se desenvolve a partir de atividades sociais das quais participa. Ao mesmo tempo, o conhecimento e as crenças do professor são influenciados por aspectos históricos e culturais, os quais formam a sociedade do qual ele faz participa.

No entendimento de Gimenez (2005), igualmente em consonância com a perspectiva sociointeracionista para a formação de professores, há sete desafios que permeiam formação de professores. O primeiro diz respeito à necessidade de definição da base de conhecimento profissional do professor. $\mathrm{O}$ segundo desafio refere-se à relevância das pesquisas na área. $\mathrm{O}$ terceiro considera a articulação entre teoria e prática. Já o quarto desafio implica o impacto e a 
sustentação das propostas que resultam das pesquisas conduzidas na área. O quinto desafio trata da situação de pesquisa das políticas públicas de formação de professores. O sexto reflete sobre a identidade profissional dos formadores de professores. $\mathrm{O}$ último desafio, o sétimo, refere-se à integração da formação inicial e continuado do docente.

Com efeito, os conceitos de internalização, mediação e zona de desenvolvimento proximal (VYGOTSKY, 2000) são considerados de acordo com os preceitos da teoria sociocultural no campo de formação docente. Desse modo, a aprendizagem humana reflete uma atividade social que, por conseguinte, é mediada e situada porque envolvem participantes interagindo em certo decurso de tempo e espaço. Quanto à internalização, há uma mudança da atividade mediada socialmente (externo) para uma atividade mediada pelo professor individualmente (interno). Isso significa que principalmente, para o professor iniciante, será possível escolher o que ensinar e como ensinar conforme a necessidade e o interesse dos alunos. A mediação deve ser entendida como um instrumento de apoio, empregada para verificar o desenvolvimento cognitivo do professor, considerando-se a zona de desenvolvimento proximal. Já a zona de desenvolvimento proximal é definida como a diferença entre o que o professor é capaz de fazer sozinho e o que ele pode fazer com a ajuda de colegas com mais experiência do que ele.

A concepção sociointeracionista também está presente nos Parâmetros Curriculares Nacionais e considera questões relativas ao contexto social, à interação e à mediação. Nessa acepção sociointeracionista, a linguagem é entendida como meio de comunicação e uma ferramenta de leitura que ocorre em um determinado momento da história e em certo espaço (VYGOTSKY, 2000). Assim, o aluno interage com outros alunos e com o professor no propósito de construir conhecimento. Todavia, para que tal processo de aprendizagem seja efetivo, é importante que o aluno entenda como tal desenvolvimento se realiza e reflita sobre o quê aprende e como aprende. Ressaltamos que no contexto deste trabalho, o professor também deve ser entendido como "aluno", pois, como discutimos anteriormente, também tratamos de questões relativos à formação de professores de línguas.

\section{Estratégias de ensino-aprendizagem de língua inglesa}

Ur (2012) salienta que no contexto de aprendizagem de línguas, a habilidade de leitura significa ler e entender e para isso é necessário ter algum conhecimento prévio sobre o assunto. Quando lemos um texto, usamos as informações transmitidas pelas palavras daquele texto 
juntamente com o nosso próprio conhecimento para entender o significado dele. A autora acredita que seja importante que o aprendiz possa estudar o texto silenciosamente no seu próprio passo, com tempo suficiente para focar no significado, diminuindo a velocidade ao encontrar palavras desconhecidas ou de difícil entendimento e praticando a estratégia de skimming em partes mais fáceis ou óbvias. Neste caso, percebe-se que a aprendizagem do vocabulário exerce um papel essencial no entendimento do texto e na velocidade desse entendimento.

Em relação a esse tópico, Ur (2012) argumenta que há alguns aspectos que o aprendiz deve aprender sobre os itens lexicais: suas formas escrita e falada, sua gramática, seu uso apropriado, expressões que costumam ser usadas juntas e as relações com outros itens na língua estrangeira e na língua materna. De acordo com a autora, as pesquisas atuais mostram que para se entender um texto, é necessário conhecer entre $95 \%$ e $98 \%$ de suas palavras.

Ainda, a autora argumenta que o significado de uma mensagem em uma situação comunicativa é transmitido pela combinação do vocabulário com a gramática. Em relação ao ensino de gramática, há situações em que a precisão gramatical é mais ou menos importante. Assim, essa precisão é mais relevante na comunicação escrita formal do que em uma fala informal ou quando o uso inadequado da gramática gera um problema de comunicação.

Goh (2012) salienta a importância de trabalhar estratégias de aprendizagem em sala de aula como uma forma de compensar pelo que os alunos ainda não sabem. Também considera que o uso de estratégias auxilia os aprendizes a alcançar o seu potencial e os torna usuários flexíveis e independentes da língua, mais reflexivos e engajados no processo de ensinoaprendizagem.

Em relação às estratégias de leitura, segundo Farrell (2003), leitores fluentes usam estratégias mais eficientes para a compreensão de um trecho do que leitores menos fluentes. $\mathrm{O}$ autor sugere as seguintes estratégias como mais eficazes: pular as palavras desconhecidas; fazer previsões sobre o significado; adivinhar o significado de palavras desconhecidas pelo contexto; nem sempre traduzir para a língua materna; procurar por cognatos; possuir algum conhecimento a respeito do tópico; fazer inferências a partir do título; perguntar a alguém quando não entender uma palavra; reler para verificar a compreensão; usar todas as informações do parágrafo e tentar compreender o significado de cada parágrafo através da sintaxe das frases (p.36-37). Percebese que essas estratégias enfatizam, mais uma vez, o conhecimento do vocabulário e o uso da gramática. $\mathrm{O}$ autor ainda menciona as estratégias de skimming (ler rapidamente para entender a ideia geral do texto) e scanning (ler rapidamente para procurar alguma informação específica) ao sugerir a seguinte estratégia de leitura para ser ensinada aos alunos: 
(1) Ativar o conhecimento prévio; (2) Prever; (3) Ler rápida e superficialmente; (4) Ler buscando detalhes; (5) Adivinhar o significado de palavras desconhecidas; (6) Reconhecer tipos de textos; (7) Identificar tópicos e ideias principais; (8) Exercícios de reconhecimento de palavras (FARRELL, 2003, p. 40).

Em consonância com a literatura mais informada sobre o tema, a qual possui um entendimento mais amplo quanto à definição do construto estratégia, a proposta de Farrell (2003) é um exemplo prático de que outras estratégias estão contidas na estratégia "guardachuva" de leitura. Como mencionamos anteriormente, a maior parte do conhecimento é adquirido por meio da leitura; portanto, é uma consequência que estratégias de leitura figurem entre as mais utilizadas e efetivas. Dessa forma, estratégias, como a de aquisição de vocabulário, são subliminares das estratégias de leitura. Pois, vejamos: para que o aluno/leitor possa ativar o conhecimento prévio sobre o tema (primeira estratégia de Farrell), ele deverá estimular o seu conhecimento sobre palavras para que recupere ideias existentes em sua memória relacionadas ao tópico. Semelhantemente, se o aluno/leitor encontrar uma palavra desconhecida e precisar determinar seu significado (estratégia cinco), há uma grande possibilidade de ele associar o vocábulo novo a algum já conhecido que compartilha a mesma raiz ou origem, ou simplesmente traduzi-la. Outrossim, para que o aluno/leitor reconheça palavras familiares, ele deverá igualmente ativar o conhecimento prévio. Vale ressaltar que todo o entendimento da leitura do texto é possível porque o aluno tem o domínio das palavras, como também detém o conhecimento gramatical de prescrições da língua.

Mencionamos brevemente na introdução que a literatura mais especializada na área tende a diferenciar entre habilidade e estratégia considerando o nível de metacognição que o aluno possui quando desempenha uma tarefa de aprendizagem. Assim, não devemos falar que a estratégia é "boa" ou "ruim", mas se ela foi empregada metacognitivamente. Isso significa que o aluno estratégico é aquele que sabe não somente quais estratégias empregar, como também quais adaptações e quais outras estratégias são necessárias durante a execução da tarefa de aprendizado. Entretanto, ao aluno pode empregar uma estratégia de maneira mais ou menos consciente, dependendo de sua metacognição. As estratégias subliminares citadas no parágrafo anterior quase sempre ocorrem de maneira mais automática, contidas umas nas outras que estão. Quanto mais automático for o uso de uma estratégia, mais conhecimento procedural o aluno está utilizando; ao contrário, quanto mais controlado for o uso de uma estratégia, mais declarativo será o conhecimento (EYSENCK, 2002). Infelizmente, a discussão sobre conhecimento procedural e declarativo extrapolam os limites deste modesto artigo. Não obstante, quando exemplificamos acima as estratégias de skimming e scanning, ativação de 
conhecimento prévio tradução, gostaríamos de salientar que saber o que é uma estratégia (knowing what) e como utilizá-la (knowing how) são pontos cruciais no desenvolvimento do aluno.

Para tanto, Carrell (1998) recomenda que os professores adotem cinco passos no intuito de direcionar os alunos no uso de estratégias:

1) Ensine aos alunos o que é uma estratégia: definição;

2) Ensine aos alunos o porquê a estratégia deve ser aprendida: explique os objetivos da tarefa e as vantagens em empregar a estratégia;

3) Explique aos alunos como usar a estratégia: dê informações detalhadas e faça uso de outras ferramentas, como as analogias e os protocolos de fala;

4) Aconselhe os alunos quando e onde a estratégia deve ser usada: sugira certas situações de aprendizagem em que o uso de uma determinada estratégia é recomendado;

5) Mostre aos alunos como avaliar o uso da estratégia: capacite os alunos a monitorarem se o uso da estrategia é eficaz ou não.

A partir dessa resumida referência teórica, a próxima seção descreve a metodologia adotada nesta pesquisa.

\section{Metodologia}

Esta pesquisa tem como objetivo relatar as percepções sobre estratégias aplicadas ao ensino e aprendizagem de língua inglesa de 30 de professores em formação, alunos do curso de Licenciatura em Letras Português-Inglês, em uma universidade tecnológica urbana no sul do país. Todos os participantes assinaram o Termo de Consentimento Livre e Esclarecido para poderem participar da pesquisa. Os participantes eram alunos regularmente matriculados na disciplina de Prática de Ensino de Língua Inglesa, composta por 60 horas e ministrada no sexto período do curso, com uma ementa ampla que trabalhava principalmente o ensino das quatro habilidades (writing, reading, listening e speaking) e três elementos (vocabulário, gramática e pronúncia) com os alunos.

Dos 30 participantes deste estudo, 23 eram do sexo feminino e sete eram do sexo masculino, com idades variando entre 20 e 63 anos (média de 24 anos). As perguntas do Questionário Metacognitivo (Apêndice 1) são um recorte do questionário original tendo sido selecionadas as perguntas que tratam das estratégias em geral, incluindo elementos de gramática, de vocabulário, as habilidades de leitura e escrita, bem como o uso da tradução em 
sala de aula. Importante ressaltar que as perguntas foram dispostas no questionário de forma que os participantes não percebessem que se tratavam de estratégias e, assim, pudessem comprometer suas respostas e o resultado desta coleta. A coleta de dados (a aplicação do Questionário Metacognitivo) ocorreu durante o período de aulas e foi aplicado ao final do semestre, após os participantes terem realizado leituras e discussões sobre os tópicos. Os participantes também foram expostos também a atividades práticas e avaliados por meio de miniaulas ministradas por eles.

A próxima seção apresenta e discute qualitativamente os resultados alcançados a partir da análise das seis perguntas do Questionário Metacognitivo.

\section{Resultados}

A primeira pergunta questionava a opinião dos alunos sobre o uso da língua materna e da tradução na sala de aula (Qual sua opinião sobre o uso da língua materna e da tradução na aula de inglês?). Os alunos, de forma geral, acreditam que a língua materna e a tradução são ferramentas auxiliares que devem ser usadas dependendo do tópico e nível de língua dos estudantes, mas de forma moderada, evitando-se exageros. Segundo alguns participantes, a língua materna "é importante para fazer paralelos com estruturas gramaticais existentes nas duas línguas" e "certas ideias e conceitos podem fazer muito mais sentido na língua materna". Já a tradução pode gerar "economia de tempo", evitando tempo desnecessário para explicar algo que pode ser mais rapidamente traduzido. Os alunos também apontaram a possibilidade de uso da tradução "como uma modalidade de ensino" feita de "maneira crítica e informada, não somente uma tradução de palavras, mas de sentido e significado".

A segunda questão perguntava que importância os participantes dão ao ensino de gramática, qual porcentagem da aula deveria ser focada nela e por quê (Que importância você dá ao ensino de gramática? Qual porcentagem da aula deveria ser focada nela? Por quê?). Os estudantes apontaram a importância da gramática pela questão estrutural da língua, argumentando que "não entender sobre ela é não entender como uma determinada língua se materializa". Nem todos responderam sobre a porcentagem da aula com foco na gramática, mas alguns mencionaram um tempo de cerca de 10 a 20 minutos ou $30 \%$ a $40 \%$ da aula dedicada a ela. Segundo um doa participantes, a gramática "não deve ser a protagonista numa aula, mas deve alicerçar o trabalho". Também destacaram o fato de que a aula não deve ser focada no ensino de gramática, mas que ela deve "fazer parte da aula como um todo em função da língua, 
não a língua girar em torno da gramática”. Ainda a esse respeito, mencionaram a importância de "expor o aluno aos usos reais da língua, por meio de textos autênticos" e contextos direcionados.

Quando questionados se é possível aprender uma língua estrangeira sem aprender gramática, na terceira pergunta, a maioria respondeu que não (É possível aprender uma língua estrangeira sem aprender gramática?). Dos 30 participantes, três responderam que não sabem ou não foram claros em relação às suas respostas, sete responderam que sim e 20 responderam que não. Os que acreditam ser possível acham que o aprendizado pode acontecer, mas de forma mais difícil. Esses argumentaram que a gramática pode ser aprendida pelo uso da língua, "assim como não aprendemos a gramática da língua portuguesa antes de utilizá-la”. Um deles foi um pouco mais radical, dizendo que tinha certeza absoluta sobre isso e que havia aprendido gramática apenas para ensinar, por ser o que esperavam dele como professor. Os alunos que responderam não ser possível aprender uma língua estrangeira sem saber a gramática dela argumentaram a partir do auxílio da gramática na estruturação das sentenças, mas também enfatizaram a importância do uso não exagerado da mesma. Um participante argumentou que “apesar de ser tão criticada, a gramática é funcional em sua totalidade, mas seu foco não deve ser tradicionalista" e outro lembrou que "a gramática faz parte da língua, sem ela cada um falaria de uma maneira diferente e não haveria compreensão".

A quarta questão perguntava que estratégias para aprendizagem e memorização de vocabulário os alunos consideravam mais importante o professor praticar com seus alunos e por quê (Que estratégias para aprendizagem e memorização de vocabulário você acha mais importante o professor praticar com seus alunos? Por quê?). Os participantes enfatizaram a importância da prática de situações próximas à realidade dos alunos, "porque eles memorizam com mais facilidade e veem sentido no que está sendo ensinado". Também apontaram as atividades criativas para fixação de vocabulário para o aluno "memorizar o conteúdo e as palavras de uma maneira natural, sem precisar decorar e repetir mecanicamente listas de palavras" e a interação como um caminho propício para a aprendizagem desse elemento. Ainda foi mencionado o contato constante com a língua e a retomada do vocabulário ensinado em aulas anteriores. A Tabela 1 mostra a frequência com que alguns termos apareceram nas respostas dos participantes, com a coluna "Número de respondentes" trazendo o número de alunos que abordaram cada estratégia. 
Tabela 1 - Frequência de termos ligados às estratégias e memorização de vocabulário

\begin{tabular}{lc}
\hline \multicolumn{1}{c}{ Termo } & $\begin{array}{c}\text { Número de } \\
\text { respondentes }\end{array}$ \\
\hline Uso de jogos & 8 \\
Leitura & 6 \\
Realidade do aluno & 5 \\
Escrita & 3 \\
Material autêntico & 2 \\
Brainstorming & 2 \\
Flashcards & 2 \\
Vídeos & 2 \\
Listening & 2 \\
Vocabulário & por \\
áreas & 1 \\
Uso de post-its & 1 \\
Mapa de palavras & 1 \\
Diálogos & 1 \\
Músicas & 1 \\
Uso de cadernos com & 1 \\
palavras novas & \\
\hline
\end{tabular}

Fonte: As autoras (2019)

Percebe-se que o uso de jogos, a leitura constante e temas próximos à realidade dos alunos foram as estratégias mais apontadas pelos respondentes. Várias outras estratégias foram relatadas, mas por um número pequeno de participantes.

As duas habilidades abordadas no questionário foram as habilidades de leitura e escrita, apesar do foco na habilidade leitora. Assim, a quinta pergunta interrogava se os alunos conseguiam nomear algumas estratégias de leitura trabalhadas e quais são consideradas mais eficazes por eles (Você consegue nomear algumas estratégias de leitura trabalhadas? Quais considera mais eficazes?). As duas estratégias mais mencionadas pelos alunos foram scanning e skimming, consideradas pela maioria como as mais eficazes. Dos 30 respondentes, 22 mencionaram o scanning e 20 mencionaram o skimming por suas utilidades práticas. Segundo um participante, a partir dessas estratégias, o aluno "não se sente pressionado a entender tudo. Ele parte de um todo para um vocabulário mais específico. Ele consegue apreender o sentido do texto partindo do contexto e palavras familiares e correlatas”. Outas estratégias mencionadas foram a previsão, inferência, ativação de conhecimentos prévios, brainstorming e leituras em duplas ou grupos seguidas por discussões. Também foi apontada a necessidade de se preparar o leitor para o texto lido e praticar a leitura em momentos distintos: uma leitura rápida 
primeiramente e outro momento com uma leitura mais aprofundada, partindo do geral para o específico.

Por fim, a sexta questão focava na importância das habilidades de escrita e leitura serem trabalhadas como processo (Qual a importância de as habilidades de escrita e leitura serem trabalhadas como processos?). Os alunos, de forma geral, percebem a relevância de essas habilidades serem trabalhadas de forma gradual, com atividades anteriores, durante e posteriores à escrita ou leitura. Acreditam que "é durante o processo que professores e alunos podem refletir melhor e de forma mais livre" e, dessa maneira, "o trabalho é conectado e significativo". Também relatam que o trabalho com a noção de processo "cria um senso de comprometimento, interesse e aperfeiçoamento". Um participante parece resumir as respostas de forma muito apropriada:

\begin{abstract}
A ideia é de que a leitura e a escrita não são produtos prontos a serem produzidos em uma única etapa. O aluno e professor precisam entender que ambas são resultantes de um processo que está em constante movimento e renovação, devendo ser trabalhadas como tais. Isso torna o aluno mais seguro, por entender que o "erro" faz parte das aprendizagens das habilidades e que sempre é possível melhorar, não há uma leitura ou escrita definitiva. Assim, as atividades de pré e pós leitura e escrita são essenciais para formar um ciclo de constante aperfeiçoamento de tais habilidades.
\end{abstract}

Considerando as introspecções dos participantes relatadas ao responderem às perguntas do Questionário Metacognitivo, podemos dizer que eles mostraram uma perspectiva positiva sobre seu aprendizado como alunos, sendo capazes de reconhecer as estratégias a serem empregadas de acordo com a situação de aprendizagem. Além disso, as indagações trazidas pelo Questionário levantaram informações sobre o entendimento dos participantes acerca de conhecimentos relevantes para sua formação como professores de línguas. Somente se o aluno tiver consciência sobre quais técnicas de aprendizagem estão a seu dispor e quais devem ser empregadas, ele terá sucesso em alcançar os objetivos da tarefa. O mesmo princípio vale para o aluno futuro professor, pois ele será capaz de ensinar sobre um conteúdo, como por exemplo, o uso de estratégias para o ensino e aprendizagem de línguas, uma vez que ele próprio souber o que é uma estratégia, como e quando usá-la e como monitorar se o emprego da estratégia está sendo efetivo.

Nesse sentido, os participantes demonstraram possuir conhecimento declarativo sobre o que é uma estratégia e como e quando utilizar, pois relataram usar algumas delas, tais como as de scanning e skimming. Podemos dizer que para explicitar o uso de uma técnica é necessário conhecê-la em sua definição e sua utilização. Para estar apto a responder ao Questionário, o participante precisou refletir sobre seu processo de aprendizagem e formação de professor e, 
por conseguinte, precisou ajustar seu nível de consciência no continuum de um conhecimento menos consciente para um mais controlado. Ao mesmo tempo, ao responderem ao Questionário Metacognitivo, os participantes empregaram estratégias de reflexão e controle de avalição de conhecimento, oscilando de mais procedural para mais declarativo, o que possibilitou seu discernimento para responderem aos questionamentos.

A próxima seção trará as considerações finais deste estudo, resumindo os resultados encontrados à luz do referencial teórico discutido anteriormente.

\section{Considerações finais}

Este trabalho teve como objetivo examinar a percepção do uso de estratégias de aprendizagem de futuros professores de língua inglesa em relação à habilidade leitora, focando não somente nas estratégias de leitura, mas também em outros elementos ligados a essa habilidade, como tradução, vocabulário, gramática e a habilidade de escrita. Para tanto, um questionário com seis perguntas foi ministrado a 30 estudantes de Licenciatura em Letras Português-Inglês ao final da disciplina de Prática de Ensino de Língua Inglesa.

De forma geral, os futuros professores apontaram visões positivas em relação ao uso de estratégia lato sensu. Entretanto, mostraram-se bastante conscientes ao fato de que esse recurso deve ser usado de forma moderada, para que uma estratégia não se sobreponha em detrimento a outra, como por exemplo, ter como objetivo de uma aula somente o ensino de gramática. Em relação à aprendizagem e memorização de vocabulário, os alunos enfatizaram a importância de praticar situações próximas à realidade dos estudantes, por meio do uso de atividades criativas e interacionais. Quanto às estratégias de leitura propriamente ditas, apesar de os participantes demonstrarem conhecer várias estratégias, tenderam a focar principalmente no scanning e skimming, duas ferramentas bastante comuns. Por fim, os participantes demonstraram considerar extremamente relevante trabalhar com as habilidades de escrita e leitura como um processo, de forma que as atividades sejam conectadas entre si e o aluno tenha tempo suficiente para o aprendizado.

Percebe-se, portanto, bastante consciência desses futuros professores de inglês em relação ao seu próprio aprendizado e ao aprendizado de seus futuros alunos. Além de terem concepções bem definidas sobre os tópicos questionados e discorrerem de forma bastante segura em suas respostas, os participantes também demonstraram conhecimento de abordagens teóricas e metodológicas e da possível aplicação delas em sala de aula. 
Em concordância com os fundamentos teóricos de Freeman e Johnson (1998) e Johnson e Dellagnello (2015), quando os alunos refletiram sobre seu comportamento estratégico, levaram em consideração a natureza de seu conhecimento teórico e mediação pelo uso das estratégias. Mais especificamente, os professores em formação foram incitados pelo Questionário Metacognitivo a refletir como a natureza de seu conhecimento sobre estratégias aplicadas ao ensino e aprendizagem de língua inglesa se desenvolve ao longo de sua formação profissional. Nessa reflexão, acreditamos que o conhecimento do futuro professor transitou de uma atividade mediada socialmente para uma atividade mediada individualmente, e que seu pensamento foi direcionado a avaliar criticamente o conteúdo e a metodologia adotados para tanto. Assim, a partir da participação no Questionário Metacognitivo, esperamos que o professor em formação tenha despertado sua zona de desenvolvimento proximal quanto ao uso de estratégias e pôde identificar quais ele domina e quais ainda precisa explorar para, por fim, ser capaz de ensinar futuramente a seus alunos (VYGOTSKY, 2000).

Pode-se apontar como limitações deste trabalho primeiramente o pequeno número de participantes, tendo em vista que utilizamos apenas uma turma de um semestre. Um novo estudo poderá acompanhar alunos/futuros professores de mais de uma turma e de instituições diferentes, em uma proposta comparativa e contrastante das percepções dos alunos/futuros professores. Um segundo fator limitante seria o número reduzido de questões apresentados no Questionário Metacognitivo. Um estudo futuro deverá conter questões específicas para cada estratégia e desmembrar o questionamento acerca dos procedimentos estratégicos empregados. Semelhantemente, uma terceira limitação diz respeito a um único instrumento de coleta de dados: o Questionário Metacognitivo. Sugere-se que um estudo futuro explore se os procedimentos estratégicos descritos pelos participantes são realmente utilizados por eles. E para tanto, recomendamos tarefas práticas nas quais os participantes tenham que empregar as estratégias descritas. Uma atividade de coleta de dados paralela também poderia contemplar observações de aula para acompanhar a execução das tarefas. Não obstantes as limitações descritas, acreditamos que este estudo possa contribuir para as áreas de formação de professores e de ensino-aprendizagem de línguas estrangeiras por mostrar resultados bastante positivos em relação à metacognição desses participantes.

\section{REFERÊNCIAS}

AEBERSOLD, J.; FIELD, M. From reader to reading teacher. Nova Iorque: CUP, 1997. 
ALMEIDA, F. University students' perception of their reading behavior in EFL. 2010, f. 177. Dissertação de Mestrado (Programa de Pós-Graduação em Inglês). Universidade Federal de Santa Catarina, Florianópolis, Santa Catarina, 2010.

ANDERSON, J. Cognitive psychology and its implications. Nova Iorque: Worth Publishers, 2015

CARRELL, P. Can strategies be successfully taught? Australian Review of Applied Linguistics, 21, (1), 1-20, 1998. Disponível em http://www.jaltpublications.org/tlt/files/98/mar/carrell.html. Acesso em 20-fev-2018.

DAVIES, F. Introducing reading. Londres: Penguin Books, 1995.

FARRELL, T. Planejamento de Atividades de Leitura para Aulas de Idiomas. São Paulo: SBS Editora, 2003.

FREEMAN, A Framework for Teacher Learning and Development. TESOL Symposium on English Teacher Development in EFL Contexts, Shantou University, Guangdong Province, China, 2006. Disponível em http://www.tesol.org/docs/default-source/new-resourcelibrary/symposium-on-english-teacher-development-in-efl-5.pdf?sfvrsn=0. Acesso em: $10 \mathrm{dez}$ 2017.

GIMENEZ, T. Desafios contemporâneos na formação de professores de línguas: contribuições da Linguistica Aplicada. In: FREIRE, Maximina M.; ABRAHÃO, Maria Helena Vieira; BARCELOS, Ana Maria Ferreira. (Org.). Linguística Aplicada e Contemporaneidade. Campinas e São Paulo: Pontes Editores e ALAB, v. 1, p. 183-201, 2005.

GOH, C. Learner Strategies. In: BURNS, A.; RICHARDS, J.C. (Orgs.). The Cambridge guide to pedagogy and practice in second language teaching. Cambridge: Cambridge University Press, 2012.

JOHNSON, K. Second language teacher education: A sociocultural perspective. New York: Routledge, (2009).

JOHNSON, K.; DELLAGNELO, A. L2/FL Teacher Education: Bridging the Complexities of Teaching and Learning Teaching. Ilha do Desterro, Florianópolis v. 68, n'1, p. 011-016, jan/abr, 2015. Disponível em: http://dx.doi.org/10.5007/21758026.2015v68n1p11. Acesso em: 15 jun. 2017.

SCHMIDT, R. Attention, Awareness, and Individual Differences in Language Learning. Disponível em: http://nflrc.hawaii.edu/PDFs/SCHMIDT\%20Attention\%2C\%20awareness \%2C\%20and\%20individual\%20differences.pdf. Acesso em: 31 ago 2011.

VYGOTSKY, L. Pensamento e linguagem. São Paulo: Martins Fontes, 2005.

UR, P. A course in English language teaching. Cambridge: Cambridge University Press, 2012. 


\section{Como referenciar este artigo}

ALMEIDA, Fabiana Vanessa Achy de; BRAWERMAN-ALBINI, Andressa. As percepções de professores de língua inglesa em formação sobre estratégias aplicadas ao ensino e aprendizagem. Rev. EntreLínguas, Araraquara, v. 5, n. 1, p. 178-194, jan./jun. 2019. E-ISSN: 2447-3529. DOI: 10.29051/el.v5i1.12794

Submetido em: 26/03/2018

Aprovado em: 12/04/2019

Publicado em: 30/04/2019 


\section{APÊNDICE 1}

1. Qual sua opinião sobre o uso da língua materna e da tradução na aula de inglês?

2. Que importância você dá ao ensino de gramática? Qual porcentagem da aula deveria ser focada nela? Por quê?

3. É possível aprender uma língua estrangeira sem aprender gramática?

4. Que estratégias para aprendizagem e memorização de vocabulário você acha mais importante o professor praticar com seus alunos? Por quê?

5. Você consegue nomear algumas estratégias de leitura trabalhadas? Quais considera mais eficazes?

6. Qual a importância de as habilidades de escrita e leitura serem trabalhadas como processos? 